\title{
Displaced juvenile Tillaux fractures
}

\section{Surgical treatment and outcome}

\author{
Thomas M. Tiefenboeck · Harald Binder · Julian Joestl · Michael M. Tiefenboeck · Sandra Boesmueller · \\ Christian Krestan · Mark Schurz
}

Received: 9 January 2015 / Accepted: 20 June 2016 / Published online: 17 August 2016

(C) The Author(s) 2016. This article is available at SpringerLink with Open Access.

\begin{abstract}
Summary
Background Approximately $15 \%$ of all juvenile injuries of the long bones involve the epiphyseal growth plate, and $2.9 \%$ of these are juvenile Tillaux fractures. The Tillaux fracture is of great importance because it involves a major weight-bearing articular surface. Treatment protocols in the literature are not uniform for this kind of fracture, and numerous case reports can be found describing various treatment methods. The aim of this study was to present the clinical outcome at long-term follow-up after treatment of displaced Tillaux fractures.

Methods In all, 168 children and adolescent patients with physeal injuries of the distal tibia were treated
\end{abstract}

\footnotetext{
Author contribution statement According to the definition given by the International Committee of Medical Journal Editors (ICMJE), the authors listed above qualify for authorship based on making one or more of the substantial contributions to the intellectual content of: (i) Conception and design [TT, MS]; and/or, (ii) Analysis and interpretation of data [TT, JJ, HB, MT, BS, CK, MS]; and/or (iii) Participated in drafting of the manuscript [TT, JJ, HB, MT, BS, CK, MS]; and/or (iv) Critical revision of the manuscript for important intellectual content [TT, JJ, HB, MT, BS, CK, MS]. Investigation performed at the Department of Trauma Surgery, Medical University of Vienna, Vienna General Hospital, Vienna, Austria.
}

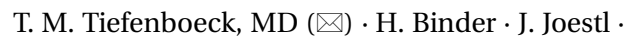
S. Boesmueller $\cdot$ M. Schurz

Department of Trauma Surgery, Medical University Vienna, Waehringer Guertel 18-20, 1090 Vienna, Austria thomas.tiefenboeck@meduniwien.ac.at

\section{Krestan}

Department of Radiology, Medical University of Vienna, Vienna, Austria

\section{M. Tiefenboeck}

Department of Orthopaedics, Herz Jesu Hospital, Vienna, Austria from 2003 to 2012. Seven patients were identified as having Tillaux fractures requiring surgical treatment and therefore were included in our study and evaluated retrospectively.

Results Seven patients with Tillaux fractures underwent surgical reconstruction by open or closed reduction. Excellent results were achieved in $90 \%$ of the patients, with a mean Foot and Ankle Score at the last follow-up of 98.71 .

Conclusion Anatomical reduction is required for every displaced epiphyseal fracture via open reduction and internal fixation, especially in cases with $\geq 2 \mathrm{~mm}$ fragment displacement. Plaster cast immobilization and non-weight-bearing mobilization for at least 4 weeks might be a good way of ensuring optimal surgical results and preventing complications.

Keywords Tillaux fracture - Operative treatment - Retrospective study - Open reduction - Foot and ankle score

\section{Introduction}

An isolated fracture of the anterolateral distal tibial epiphysis is called juvenile Tillaux fracture. Paul Jules Tillaux first described the avulsion fracture of the distal tibial physis in 1892 [1]. Approximately $15 \%$ of all juvenile injuries of the long bones involve the epiphyseal growth plate [2], fractures of the distal tibial epiphysis account for $11-20 \%$ to these injuries [3], and $2.9 \%$ of these are juvenile Tillaux fractures [4]. Triplane and Tillaux fractures occur after supination external rotation and compression stress with unpredictable multiplanar fracture patterns [5]. The open region represents an area of weakness in the distal tibia with a risk for Tillaux fractures [6]. Because the fracture can appear different on X-ray images, computed tomography is often necessary to deter- 


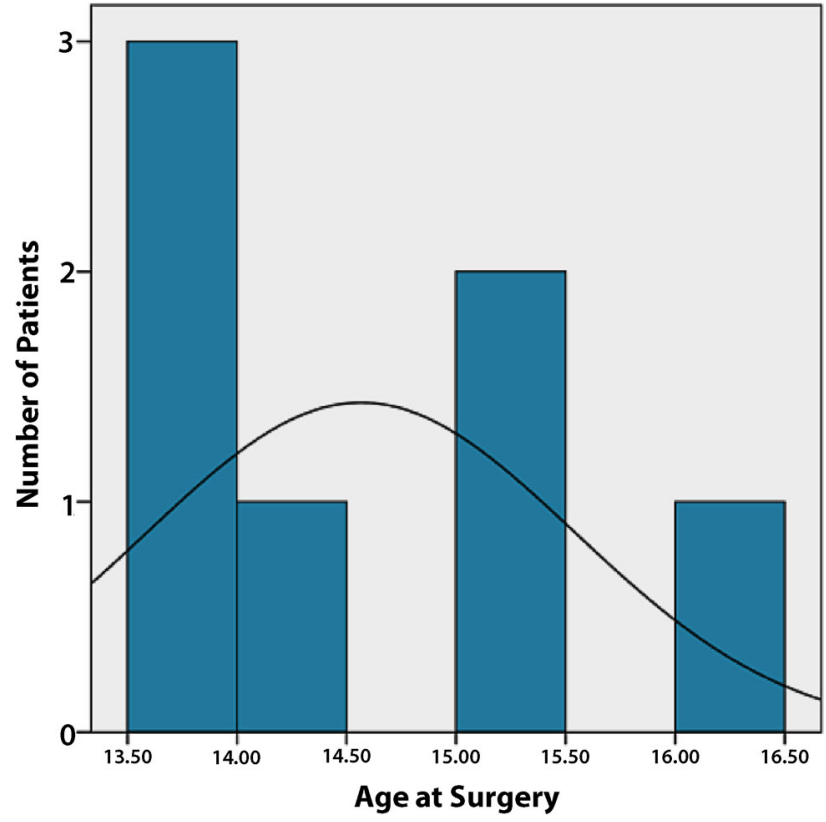

Fig. 1 Overview of patients' age at the time of surgery

mine the number of fragments [5, 7]. All of these fractures are intra-articular and therefore anatomic or near-anatomic reduction of the joint surface is recommended to minimize future posttraumatic ankle arthritis [5], joint stiffness, and pain [6]. The fracture is of great importance because it involves a major weight-bearing articular surface [8]. Most of these fractures occur at the end of growth, and growth arrest occurs rarely [5].

In the literature the treatment protocols for this kind of fracture are not uniform, therefore a great number of case reports can be found describing various treatment methods [8-10]. The treatment procedures of this fracture are based on the displacement. Nondisplaced or minimally displaced $(<2 \mathrm{~mm})$ fractures can be treated by immobilization with casts, whereas most of the authors conclude that for a displacement of over $2 \mathrm{~mm}$, closed or open reduction is necessary to restore articular congruity [3, 11-13].

This study presents, to our knowledge, one of the largest single-center reports on displaced juvenile Tillaux fractures in recent literature focusing on the clinical-functional and radiographic outcome.

\section{Methods}

From 2003 to 2012, 168 patients with physeal injuries of the distal tibia were treated at the Department of Trauma Surgery and evaluated for retrospective follow-up. Included were all patients who underwent primary treatment of physeal injuries at our Department of Trauma Surgery. Diagnosis was based on clinical and recognized radiological criteria. All patient information, disease-, and treatment-related data were retrieved by a review of the patients' charts. Prior to the investigation, the corresponding institutional review board approved this study (EK Nr. 1216/2014).

Seven out of 168 patients met the inclusion criteria, comprising four male (57\%) and three female (43\%) patients with a mean age of 15 years (range, 14-16 years); details of the age distribution are presented in Fig. 1.

The first assessment involved a clinical examination, an X-ray in two planes, and in all but one patient a computed tomography (CT) study. An examination clarifying the state of the skin and the neurovascular status is necessary to indicate emergency surgery.

All patients were closely followed up until removal of the implants was possible. After screw removal, wound healing, and full recovery of function, there is no need to follow up patients closely and they were told to come back if complications occurred.

However, for this study all patients were invited for follow-up investigation by letter or telephone call. All patients signed informed consent forms before the investigation.

Data of five out of seven patients were available for a mean long-term follow-up of 79 months (range, 40.43-126.80 months).

Every clinical chart, X-ray, and/or CT scan was reviewed. All X-rays and CT scans were analyzed by two blinded investigators (one radiologist with 20 years of experience and one trauma surgeon with 14 years of experience) establishing the fracture type. In all patients, the Foot and Ankle Score [14] was recorded after a mean time of 6 months and at the last followup, after a mean of 79 months.

In this case series all but one fracture $(>2 \mathrm{~mm}$ ) was treated by open reduction and internal fixation (ORIF) to achieve anatomic reduction with additional plaster cast immobilization for at least 4 weeks (non-weightbearing).

\section{Statistical analysis}

Descriptive data (mean, median, range, proportions) are reported for the entire patient cohort. Statistical analysis focused on surgical, radiographic, and functional outcome after treatment of a Tillaux fracture. Therapeutic variables (surgery, adjuvant therapy, and function), pathological variables (refracture, complications), and demographic variables (sex, age and follow-up) were examined. All calculations were made using Microsoft Excel ${ }^{\circledR}$, SPSS $^{\circledR}$ software (Version 21.0, SPSS Inc., Chicago, Ill.).

\section{Results}

All patients presented first with pain and swelling at the outpatient clinic, one patient presented additionally with a malposition of the ankle. After initial X-ray and CT scan (86\%), a fracture dislocation ( $>2 \mathrm{~mm}$ ) requiring operative fracture reduction was found in all patients. Therefore, screw fixation was used for 
Table 1 Overview of patient characteristics

\begin{tabular}{|c|c|c|c|c|c|c|c|c|c|}
\hline $\begin{array}{l}\text { Case } \\
\text { no. }\end{array}$ & Sex/Age (years) & Cause & $\begin{array}{l}\text { Foot and Ankle } \\
\text { Score }<1 \text { year }\end{array}$ & $\begin{array}{l}\text { Foot and Ankle } \\
\text { Score }>3 \text { years }\end{array}$ & $\begin{array}{l}\text { Treatment } \\
\text { method }\end{array}$ & $\begin{array}{l}\text { Length of } \\
\text { follow-up in } \\
\text { months }\end{array}$ & $\begin{array}{l}\text { Cast immobiliza- } \\
\text { tion in weeks }\end{array}$ & CT & Complication \\
\hline 1 & M/16.27 & Sport injury & 100 & 100 & ORIF & 52.8 & 8 & Yes & - \\
\hline 2 & $F / 13.82$ & Sport injury & 91 & 100 & ORIF & 126.8 & 5 & Yes & - \\
\hline 3 & $F / 13.67$ & Sport injury & 100 & 100 & ORIF & 40.4 & 5 & Yes & - \\
\hline 4 & $M / 15.26$ & Sport injury & 91 & n.e. & CRIF & 4.3 & 6 & Yes & $\begin{array}{l}\text { Limitation of } \\
\text { ankle move- } \\
\text { ment }\end{array}$ \\
\hline 5 & $\mathrm{M} / 14.15$ & Sport injury & 95 & 100 & ORIF & 73.7 & 6 & No & - \\
\hline 6 & M/15.00 & Accident & 100 & n.e. & ORIF & 7.0 & 4 & Yes & - \\
\hline 7 & $F / 13.79$ & Sport injury & 100 & 100 & ORIF & 101.6 & 4 & Yes & - \\
\hline
\end{tabular}

all patients. Six fractures (86\%) needed ORIF; one ( $14 \%)$ could be treated by percutaneous fracture reduction and internal fixation (CRIF). All patients were treated with an over-knee plaster cast immobilization after the surgical procedure for at least 4 weeks (range, 4-8 weeks). In all but one patient non-weight-bearing mobilization was carried out for 4 weeks; for the rest with cast immobilization partial weight-bearing was allowed in all patients (see Table 1 for detailed patient information).

Overall six patients $(86 \%)$ had full and immediate recovery without suffering any complications, with a mean Foot and Ankle Score after 4 months of 96.71 points (range, 91.00-100.00; median 100.00). The Foot and Ankle Score improved over time and could be evaluated after a mean of 79 months in five patients, presenting with 100 points at the latest follow-up.

One patient presented with pain and joint stiffness during the follow-up period. The limitation of the ankle joint of $15^{\circ}$ was treated conservatively by physical therapy and disappeared over a short time period. At the end of the study, the patient was free of complications and satisfied with the operative result.

Analyzing the trauma mechanism, we found six injuries occurring during sporting activities and one injury uring a walking accident.

At every follow-up date, X-rays in two planes were made to assess fracture healing and to check for osteosynthesis. Additional clinical examinations were performed. A trauma surgeon specialized in children performed follow-up investigations. Patients were followed up very closely every week until cast immobilization was over and then at 3-month intervals until full mobilization was possible.

In five patients $(71 \%)$ the screws were removed after a mean time of 8 months (range, 6.07-8.93 months; median 8.13 months). Osteosynthesis material was removed because of the patients' and parents' wish.

One patient moved back to the USA and another patient moved back to Russia before screw removal; both were satisfied with their operative results and presented with excellent clinical/functional outcome at the latest follow-up.

An exemplary case of a 14-year-old patient with a surgically treated Tillaux fracture is presented in Figs. 2 to 5 (Fig. 2a, b, X-ray; Fig. 3a, b, CT scan; Fig. 4a, b, X-ray after open reduction and screw fixation; Fig. 5a, b, X-ray in two planes after screw removal).

\section{Discussion}

The juvenile Tillaux fracture is defined as a fracture of the anterior distal tibial tubercle only occurring in adolescents. Paul Tillaux first described this fracture type from cadaveric studies in 1892 [1]. Today this fracture type is classified as a Salter-Harris type III fracture of the distal tibial epiphysis and is only seen in adolescents. Tillaux fractures and triplane fractures are the most common ankle joint fractures in adolescents with closure of the epiphyseal plate according to the mechanism of injury [5].

A review of the literature revealed only a few studies [5, 11-17] dealing with this type of fracture and most of them were case reports or case series.

We report on one of the largest case series of patients with displaced Tillaux fractures treated in one single institution. In summary, our study shows that ORIF and postoperative plaster cast immobilization lead to excellent results in displaced Tillaux fractures. There are certainly considerable limitations to this study, mainly its solely retrospective design, small cohort, and long duration of treatment, all explained by the nature of this injury. However, we used homogeneous treatment guidelines for all patients, but it is not possible to make a categorical statement because of the solely retrospective nature of the study and the small number of patients.

Owing to the low patient number, only a descriptive statistical analysis was performed. All patients presented at the last follow-up examination with excellent clinical results according to movement and weight-bearing, and therefore no further follow-up investigations were planned. Based on this knowledge, 
Fig. 2 InitialX-ray in two planes of a Tillaux fracture in a 14-year-old patient (a anteroposterior view, b lateral view)
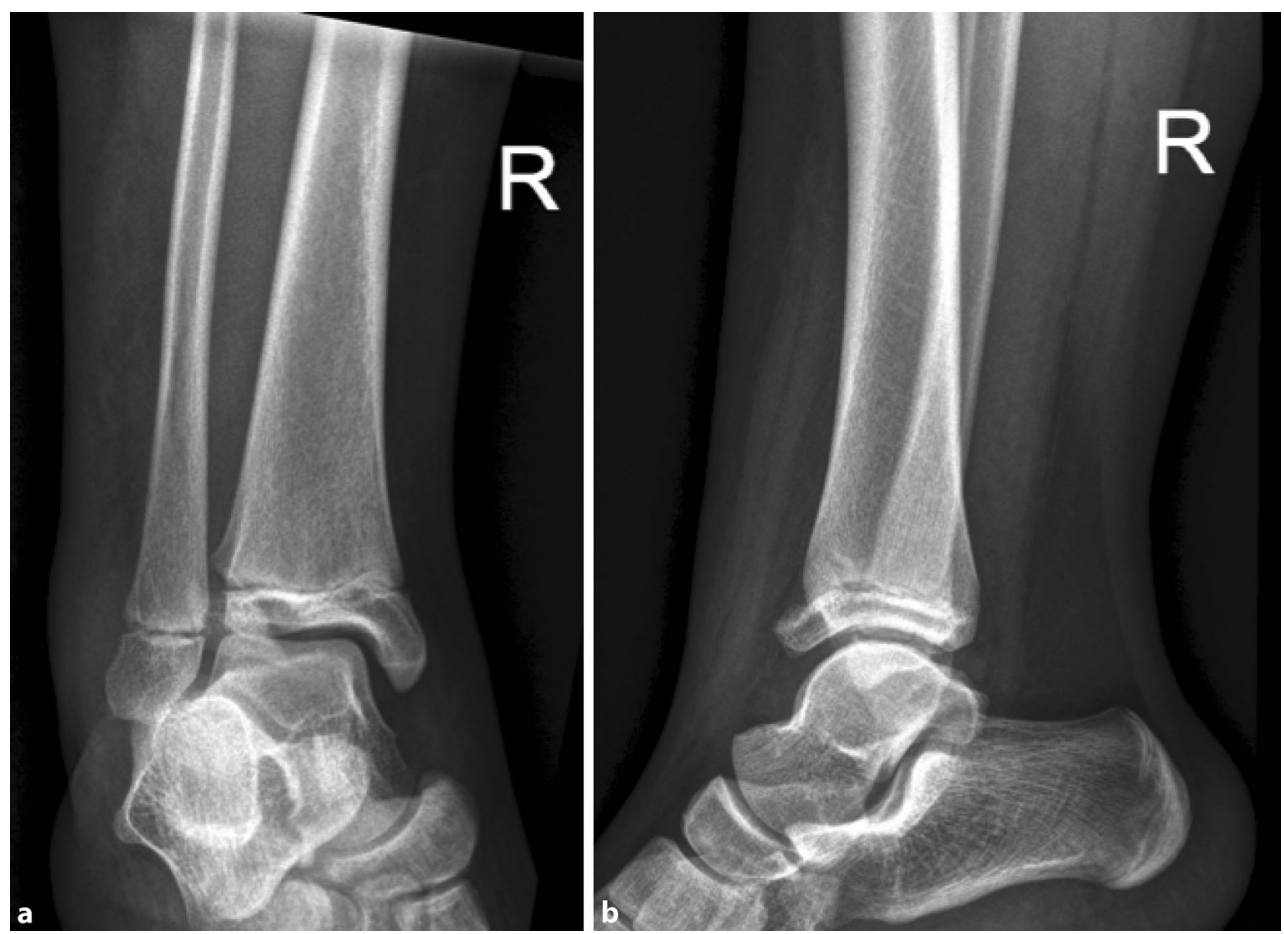

Fig. 3 CT scan, coronal (a) and axial plane $(\mathbf{b})$ of a Tillaux fracture in a 14-year-old patient
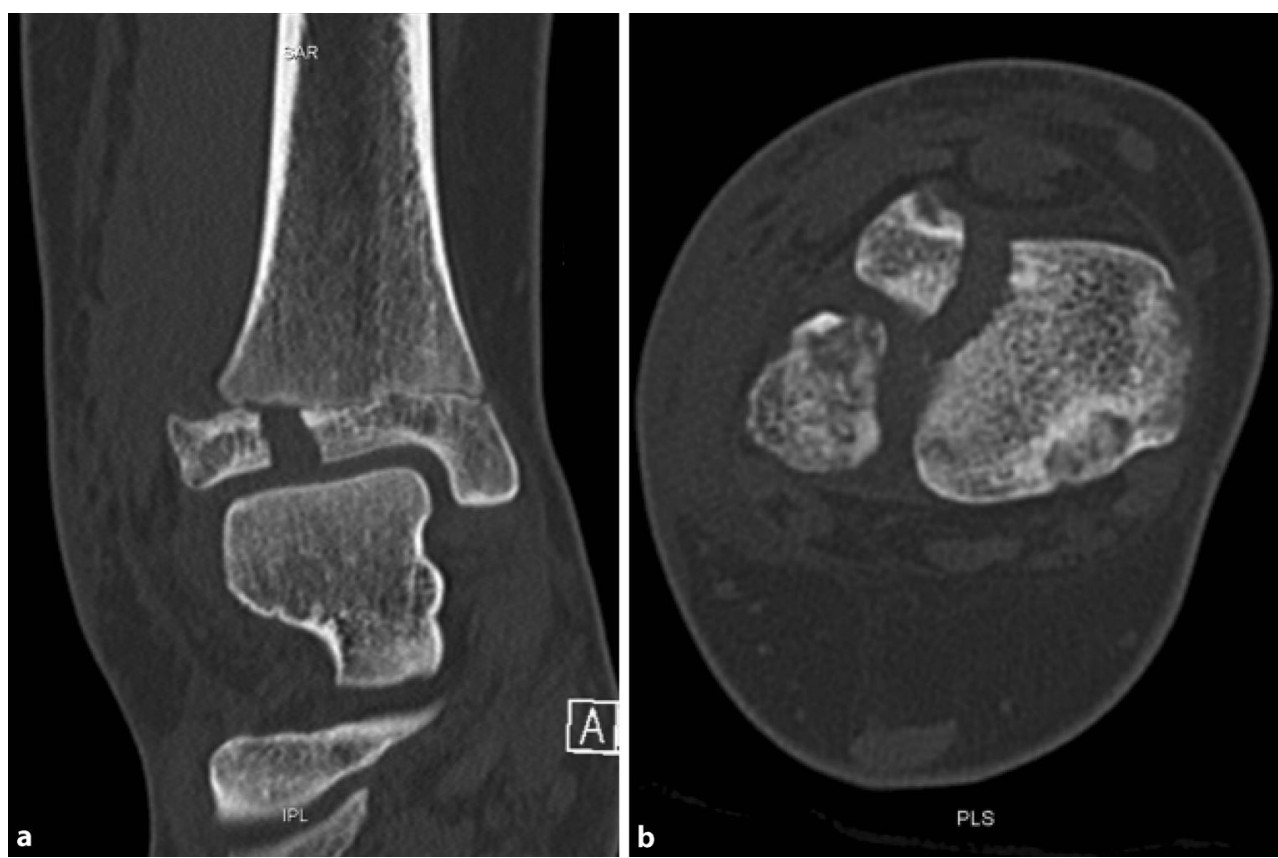

the data analysis has to be reviewed critically since it might overlook the risk of long-term complications.

All of our patients presented with an excellent foot and ankle score at the last follow-up (mean Foot and Ankle Score, 98.71). Diagnosis was made using X-rays in two planes and additional CT scans to assess the extent of damage of a comminuted fracture and the articular surface, which is the standard procedure for diagnosing this injury $[6,18]$.

Some authors prefer ORIF of fractures with more than $2 \mathrm{~mm}$ of displacement $[11,19]$, which is in ac- cordance with the general principles of treatment and was also done in our series. Except for one patient, all patients in our study were treated by ORIF and additional postoperative plaster cast immobilization. If possible, closed reduction and internal fixation can also be used for treatment [13], but was only performed on one of our patients.

Depending on patient's age, owing to the long study period (10 years) and finally surgeons own decision the time of plaster cast immobilization varied between 4 and 8 weeks. All patients were treated with non- 
Fig. 4 X-ray in two planes after open reduction and screw fixation in a 14-yearold patient (a anteroposterior view, b lateral view)
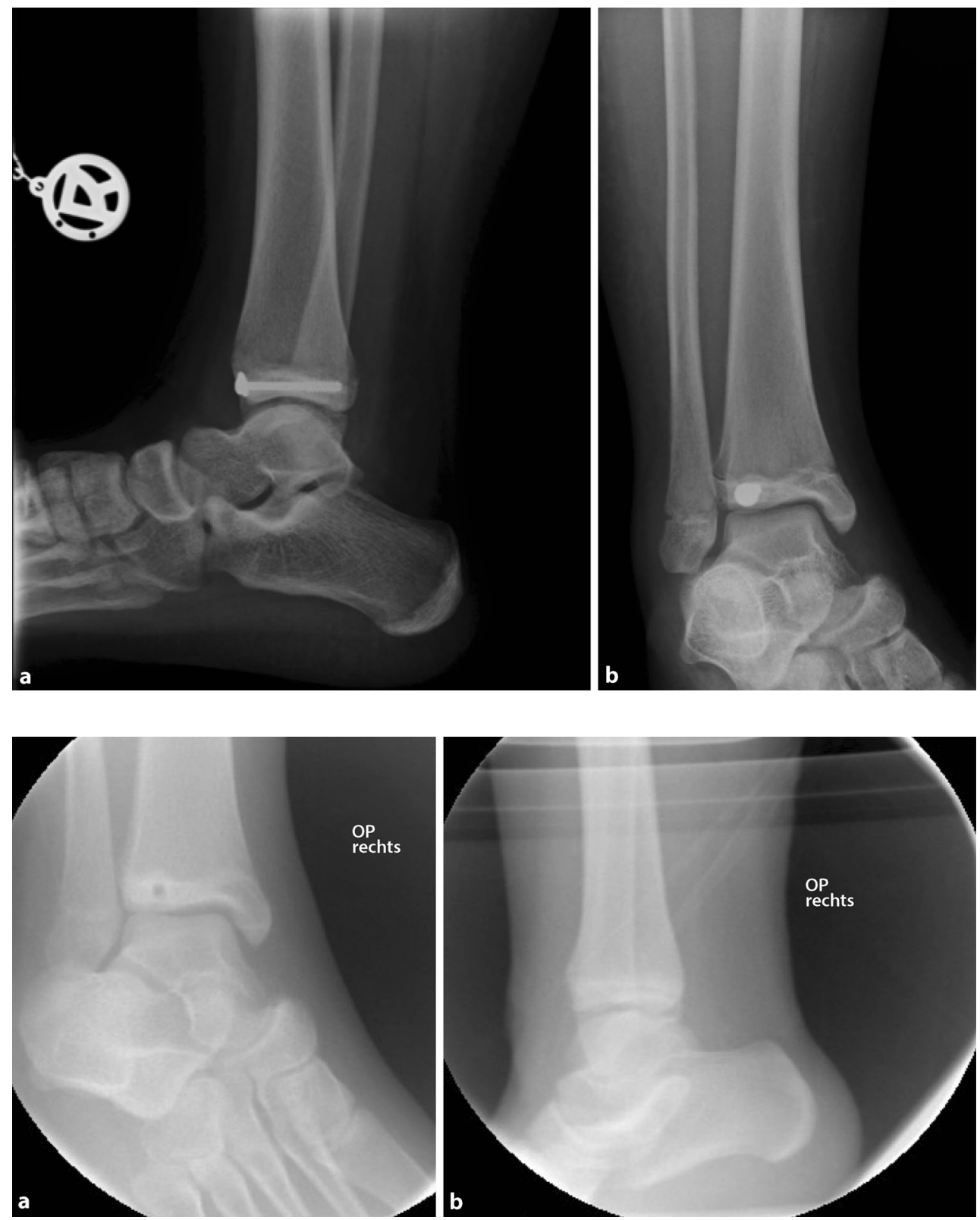

Fig. 5 X-ray in two planes after screw removal in a 14year-old patient (a anteroposterior view, b lateral view)

weight-bearing mobilization for at least 4 weeks with plaster cast immobilization to secure treatment outcome, although this is not described as standard treatment in the literature. We prefer an overall treatment with plaster cast immobilization to avoid compliance problems and secure good results as is also described by different authors in the literature $[11,20]$.

The complication rate of closed or open reduction with internal fixation is very low, as in our study. The lack of complications after surgery at the longest follow-up suggests that open reduction with internal fixation is a safe procedure for treatment of this type of fracture [21].

In all but one patient, ORIF was used, which is a safe procedure, as mentioned earlier, and justifies the short follow-up time if patients present with excellent clinical results after a mean of 6 months (mean
Foot and Ankle Score 96.71<1 year postoperatively). However, in five patients long-term follow-up data were available, showing excellent results with a Foot and Ankle Score of 100 and satisfaction in all patients.

In the literature, arthroscopic-assisted reduction and fixation of these fractures is also an established treatment option. By arthroscopy, direct visualization of the fragment and interpretation of associated chondral injuries is possible. Reviewing the literature we only found cases series describing this method and therefore we did not use it in our patients routinely $[8,22,23]$.

To the best of our best, after reviewing the current literature (PubMed and Cochrane Library) we found only eight studies dealing with Tillaux fractures and numerous case reports. Table 2 presents the results of the studies in detail excluding case reports. 
Table 2 Overview of the current literature

\begin{tabular}{|c|c|c|c|c|c|c|c|c|c|}
\hline Author and year & Patients $(n)$ & Treatment & CT & X-ray & Complications & Outcome & $\begin{array}{l}\text { Cast immobi- } \\
\text { lization }\end{array}$ & Follow-up & $\begin{array}{l}\text { PDF } \\
\text { available }\end{array}$ \\
\hline Choudhry I. et al. 2013 [13] & 20 & ORIF and CRIF & - & - & - & $\begin{array}{l}\text { Excellent, } \\
\text { Foot and } \\
\text { Ankle } \\
\text { Score, } \\
\text { Marx } \\
\text { Activity } \\
\text { Score }\end{array}$ & - & $>2$ years & No \\
\hline Gourineni P. et al. 2011 [20] & 8 & ORIF & Yes $(7 / 8)$ & Yes & $\begin{array}{l}\text { In } 3 \text { patients; } \\
\text { Achilles con- } \\
\text { tracture; bro- } \\
\text { ken screws }\end{array}$ & No & 4 weeks & $>1$ year & Yes \\
\hline Dias L.S. et al. 1983 [24] & 8 & - & - & - & - & - & - & - & No \\
\hline Cottalorda J. et al. 2008 [21] & 30 & ORIF & - & - & - & - & - & $\begin{array}{l}\text { Mean } \\
3 \text { years }\end{array}$ & No \\
\hline Kaya A. et al. 2007 [11] & 10 & ORIF & Not needed & Yes & $\begin{array}{l}10^{\circ} \text { loss of } \\
\text { plantar flexion } \\
\text { in } 2 \text { patients, } \\
\text { in } 1 \text { patient } \\
\text { limitation of } \\
\text { recreational } \\
\text { activities }\end{array}$ & $\begin{array}{l}\text { AOFAS } \\
\text { mean } \\
99.3\end{array}$ & 6 weeks & $\begin{array}{l}\text { Mean } \\
54 \text { months }\end{array}$ & Yes \\
\hline Schlesinger I. et al. 1993 [10] & 6 & CRIF & $\begin{array}{l}\text { Not men- } \\
\text { tioned }\end{array}$ & Yes & None & - & - & - & Yes \\
\hline Stefanich R. et al. 2007 [3] & 5 & $\begin{array}{l}\text { ORIF and } \\
\text { conservative } \\
\text { (1) }\end{array}$ & - & Yes & - & $\begin{array}{l}\text { Excellent, } \\
\text { No score } \\
\text { used }\end{array}$ & Not mentioned & $\begin{array}{l}1 \text { to } \\
9 \text { years }\end{array}$ & No \\
\hline Kling T. et al. 1984 [25] & $\begin{array}{l}32 \text { (com- } \\
\text { bined } \\
\text { Salter Har- } \\
\text { ris III and } \\
\text { IV) }\end{array}$ & $\begin{array}{l}\text { Conservative } \\
\text { therapy -(9) } \\
\text { and ORIF }\end{array}$ & - & - & $\begin{array}{l}\text { Growth distur- } \\
\text { bance }(5 / 9)\end{array}$ & $\begin{array}{l}\text { Excellent } \\
\text { No score } \\
\text { used }\end{array}$ & - & - & No \\
\hline Current Study & 7 & $\begin{array}{l}\text { ORIF and CRIF } \\
\text { (1) }\end{array}$ & Yes $(6 / 7)$ & Yes & $\begin{array}{l}\text { Wound healing } \\
\text { disturbance; } \\
15^{\circ} \text { loss of } \\
\text { flexion }\end{array}$ & $\begin{array}{l}\text { Excellent, } \\
\text { Foot and } \\
\text { Ankle } \\
\text { Score }\end{array}$ & 4 to 8 weeks & $\begin{array}{l}\text { Mean } \\
58 \text { months }\end{array}$ & - \\
\hline
\end{tabular}

The fracture location, degree of displacement, and the child's age determine the correct treatment of pediatric ankle fractures. We claim to reduce epiphyseal injuries anatomically in every case by open means in accordance with the existing literature $[11,21]$.

Our results underline that every Tillaux displacement exceeding more than $2 \mathrm{~mm}$ should be corrected anatomically at every age to achieve excellent results.

\section{Conclusion}

Anatomical reduction is required in every displaced Tillaux fracture, especially in cases with $\geq 2 \mathrm{~mm}$ fragment displacement.

Our results highlight that only an absolute anatomical fracture reduction and internal fixation can prevent a bone bridge and a consecutive epiphysiodesis with axial malalignment and limb length discrepancy, resulting in excellent clinical and radiological results. Plaster cast immobilization and non-weight-bearing mobilization for at least 4 weeks might be a good tool to ensure surgical results and prevent complications.
Open access funding provided by Medical University of Vienna.

Conflict of interest T.M. Tiefenböck, H. Binder, J. Jöstl, M.M. Tiefenböck, S. Boesmueller, C. Krestan, and M. Schurz declare that they have no competing interests.

Open Access This article is distributed under the terms of the Creative Commons Attribution 4.0 International License (http://creativecommons.org/licenses/by/4.0/), which permits unrestricted use, distribution, and reproduction in any medium, provided you give appropriate credit to the original author(s) and the source, provide a link to the Creative Commons license, and indicate if changes were made.

\section{References}

1. Koury SI, Stone CK, Harrell G, La Charite DD. Recognition and management of Tillaux fractures in adolescents. Pediatr Emerg Care. 1999;15(1):37-9.

2. Schurz M, Binder H, Platzer P, Schulz M, Hajdu S, Vecsei V. Physeal injuries of the distal tibia: long-term results in 376 patients. IntOrthop. 2010;34(4):547-52.

3. Stefanich RJ, Lozman J. The juvenile fracture of Tillaux. Clin Orthop RelatRes. 1986;210:219-27. 
4. Spiegel PG, Cooperman DR, Laros GS. Epiphyseal fractures of the distal ends of the tibia and fibula. A retrospective study of two hundred and thirty-seven cases in children. JBone Joint SurgAm. 1978;60(8):1046-50.

5. Crawford AH. Triplane and Tillaux fractures: is a $2 \mathrm{~mm}$ residual gap acceptable? J Pediatr Orthop. 2012;32(Suppl 1):S69-S73.

6. Horn BD, Crisci K, Krug M, Pizzutillo PD, MacEwen GD. Radiologic evaluation of juvenile tillaux fractures of the distal tibia. J Pediatr Orthop. 2001;21(2):162-4.

7. Lemburg SP, Lilienthal E, Heyer CM. Growth plate fractures of the distal tibia: is CT imaging necessary? Arch Orthop TraumaSurg. 2010;130(11):1411-7.

8. Panagopoulos A, van Niekerk L. Arthroscopic assisted reduction and fixation of a juvenile Tillaux fracture. Knee Surg Sports Traumatol Arthrosc. 2007;15(4):415-7.

9. Leary JT, Handling M, Talerico M, Yong L, Bowe JA. Physeal fractures of the distal tibia: predictive factors of premature physeal closure and growth arrest. J Pediatr Orthop. 2009;29(4):356-61.

10. Schlesinger I, Wedge JH. Percutaneous reduction and fixation of displaced juvenile Tillaux fractures: a new surgical technique. J Pediatr Orthop. 1993;13(3):389-91.

11. Kaya A, Altay T, Ozturk H, Karapinar L. Open reduction and internal fixation in displaced juvenile Tillaux fractures. Injury. 2007;38(2):201-5.

12. Duchesneau S, Fallat LM. The Tillaux fracture. J Foot Ankle Surg. 1996;35(2):127-33.

13. Choudhry IK, Wall EJ, Eismann EA, Crawford AH, Wilson L. Functional outcome analysis of Triplane and Tillaux fractures after closed reduction and Percutaneous fixation. JPediatr Orthop. 2013;:. doi:10.1097/bpo.0000000000000085.

14. Kim JR, Song KH, Song KJ, Lee HS. Treatment outcomes of triplane and Tillaux fractures of the ankle in adolescence. Clin Orthop Surg. 2010;2(1):34-8.
15. Wuerz TH, Gurd DP. Pediatric physeal ankle fracture. J Am Acad Orthop Surg. 2013;21(4):234-44.

16. Tanaka M, Shibano K, Tagawa Y, Kawai H, Hamada M. Juvenile Tillaux fracture with disrupted anteroinferior tibiofibular ligament: a case report. Knee Surg Sports TraumatolArthrosc. 2009;17(10):1239-42.

17. Kennedy MA, Sama AE, Padavan S. The Tillaux fracture: a case report. JEmerg Med. 1998;16(4):603-6.

18. Ayyagari S, Bancroft LW. Radiologic case study. Diagnosis: juvenile tillaux fracture. Orthopedics. 2010;33(3):134.

19. Rosenbaum AJ, DiPreta JA, Uhl RL. Review of distal tibial epiphyseal transitional fractures. Orthopedics. 2012;35(12):1046-9.

20. Gourineni P, Gupta A. Medial joint space widening of the ankle in displaced Tillaux and Triplane fractures in children. JOrthop Trauma. 2011;25(10):608-11.

21. Cottalorda J, Beranger V, Louahem D, Camilleri JP, Launay F, Dimeglio A, et al. Salter-Harris Type III and IV medial malleolarfractures: growth arrest: isitafate? Aretrospective study of 48 cases with open reduction. J Pediatr Orthop. 2008;28(6):652-5.

22. Miller MD. Arthroscopically assisted reduction and fixation of an adult Tillaux fracture of the ankle. Arthroscopy. 1997;13(1):117-9.

23. Jennings MM, Lagaay P, Schuberth JM. Arthroscopic assisted fixation of juvenile intra-articular epiphyseal ankle fractures. J Foot Ankle Surg. 2007;46(5):376-86.

24. Dias LS, Giegerich CR. Fractures of the distal tibial epiphysis in adolescence. The Journal of bone and joint surgery American volume. 1983;65(4):438-44.

25. Kling TF, Jr., Bright RW, Hensinger RN. Distal tibial physeal fractures in children that may require open reduction. The Journal of bone and joint surgery American volume. 1984;66(5):647-57. 